\title{
La incorporación de tecnicismos mineros a la lexicografía académica decimonónica
}

\author{
Miguel Ángel Puche Lorenzo* \\ Universidad de Murcia
}

Una lengua, a partir del surgimiento de nuevos referentes extralingüísticos, debe ampliar su capacidad designativa y para ello se puede valer de una serie de recursos semánticos, morfológicos o léxicos, es decir, un mismo vocablo puede servir para designar dos objetos o acciones diferentes; en el primer caso, podemos crear nuevos términos valiéndonos de prefijos y sufijos derivativos, o recurrir a la creación a partir de la unión de dos lexemas, composición, la creación onomatopéyica o el préstamo léxico. En cualquiera de los casos, revisados someramente, estaremos asistiendo a la presencia de neologismos en una lengua, neologismos que, con el paso del tiempo y a raíz de la aceptación de los hablantes y su incorporación a los repertorios lexicográficos, formarán parte del caudal léxico de una lengua ${ }^{1}$.

Sin embargo, estas cuestiones se pueden volver más confusas cuando nos centramos en un ámbito lingüístico que se aleja de la lengua común y pertenece a un campo especializado. Un hecho que no impide que, tras la aceptación de los hablantes, un nuevo término pase a formar parte de la lengua común ${ }^{2}$. De hecho, actualmente estamos recibiendo

* Un avance de este trabajo se presentó como conferencia en el XXVI Curso de Lingüistica Textual, Universidad de Murcia. Se ha realizado merced a una beca postdoctoral de la Fundación Cajamurcia en el marco del proyecto $\mathrm{PB} / 16 / \mathrm{FS} / 02$ financiado por la Fundación Séneca.

1 Vid. Alvar Ezquerra (1996), Almela (1999) Pena (1999 y 2000), Lang (1992) y Bajo Pérez (1997).

2 Vid. Frago Gracia (1989), Díez de Revenga Torres (2001) y Fort (2001). 
un amplio aporte terminológico del mundo de Internet: página web (o site web), word, DVD, CD-ROM, e-mail,... formaciones que estamos acogiendo y aceptando como préstamos lingüísticos, a los que sometemos a los mecanismos de derivación del español, como webones, en el español de América, y en la mayoría de los casos están considerados o se ven utilizados como parte de la lengua común, cuando provienen de un ámbito especializado. Ante estos neologismos conocemos la aceptación de los usuarios de la lengua pero su inclusión en el diccionario académico parece no estar tan acorde con los primeros. En la última edición del DRAE (DRAE-2001), los lemas web, DVD, o CD-ROM tienen entrada en él, sin embargo word o e-mail, no, aunque sí se recoge $c o$ rreo electrónico dentro de las acepciones de correo. Estos ejemplos nos sirven para comprobar cuál es la actitud de los hablantes, por un lado, y la de la lexicografía académica, por otro, algo que no es nuevo, como tendremos la ocasión de constatar. A partir de ella nos trasladaremos al siglo XIX y a un campo de trabajo diferente: la minería.

A partir del siglo XVIII se produce un avance considerable en la evolución de las ciencias modernas, avance que se dejará notar con mayor peso en el siglo XIX y se trasluce en la lengua a raíz de la creación de un vocabulario científico y técnico acorde con la nueva terminología que estaba surgiendo y venía importada, muchas veces, de países europeos donde la difusión de los conocimientos científicos contaba con gran apoyo y producía considerables avances y descubrimientos sorprendentes para la sociedad del momento. España intenta integrarse en la corriente científica europea, aunque sin lograr los resultados y el suficiente adelanto científico de los vecinos ultrapirenaicos. La Corona española pretendió impulsar la ciencia durante el XVIII, pero al estar ésta sometida a ella, intentar enfocarla a sus necesidades más inmediatas y depender, como resultado de todo esto, de la experiencia extranjera, no consiguió asentar unas bases sólidas ni crear una Academia de las Ciencias quedando ya, en el XIX, el desarrollo de la ciencia al amparo de aquellas asociaciones o círculos sociales que se habían hecho eco del camino emprendido en Europa ${ }^{3}$. De este modo, 
merece especial atención el periódico Discursos mercuriales que se empieza a publicar en la segunda mitad del XVIII, así como la fundación de la Real Sociedad Bascongada de los Amigos del País. A través del primero la introducción de la terminología científica encuentra un buen método para difundirse, mientras que a raíz de la Real Sociedad se persigue la formación científica de sus miembros mediante el conocimiento de las ideas científicas que se propagaban en Europa. No es de extrañar que las disciplinas que suscitaban mayor interés en la Sociedad fueran la Mineralogía, la Metalurgia, la Física y la Química4.

Éstos son los antecedentes que prepararon el camino para la eclosión científica en España, aunque principalmente sirviera para recibir las influencias y no para aportarlas, por lo menos en un primer momento y en lo que a la terminología se refiere. Si nos detenemos en Murcia y en el estudio particular que pretendemos realizar, observaremos cómo en este siglo, el XIX, se inicia el auge de la actividad minera. Mazarrón, La Unión o Cartagena habían sido focos mineros explotados por fenicios, griegos y romanos. La riqueza mineral había atraído a los pueblos que colonizaron la Península Ibérica, pero esas explotaciones fueron abandonadas hasta que, durante el siglo XIX, vuelve a despertar interés la riqueza minera de la zona. Las viejas explotaciones mineras vuelven a ser reutilizadas a la vez que se empiezan a crear nuevos pozos y se abren numerosas galerías. Esto se verá reflejado en el crecimiento económico, las migraciones de mano de obra procedente de regiones vecinas, así como la captación del interés internacional, dada la riqueza de los materiales que se extraían en las minas de la zona. Como fruto de este desmesurado crecimiento, recordemos que Gustare Eiffel, constructor de la Torre que lleva su nombre en París, realizó algunos de sus proyectos para La Unión. La vitalidad minera había traspasado las fronteras nacionales y compañías internacionales habían fijado su vista en la rica producción mineral. En el periódico $E l$ Minero, 25 de mayo de 1841, leemos: "el minero no se propone mas que promover e impulsar la naciente industria según su sistema y su talento... tanto minado antigo [sic], aquellos montones de escoriales y te-

4 Vid. Gómez de Enterría (2001). 
rreros ó minerales preparados por la calcinación para entrar en la fábrica..." y de su riqueza nos habla el publicado el 20 de mayo de ese mismo año: "minas de vermellon, de estaño, de cobalto, de cobre y de hierro y cítase un no pequeño catálogo de piedras preciosas, entre las que figuran por supuesto las esmeraldas, rubíes, zafiros, granates y todas las especies de mérito pertenecientes al género silíceo".

Dentro del auge de las disciplinas científicas se encuentra la Minería, en estrecha relación con la Química ${ }^{5}$, como veremos más adelante, a la que pertenecerán numerosos y novedosos términos técnicos, específicos de ella, que empezarán a propagarse con mayor o menor suerte. Esta avalancha de tecnicismos, justificada por el desarrollo de las ciencias, recibirá una "especial acogida" en los repertorios lexicográficos del XIX. La Real Academia Española, fundada en el siglo XVIII, editó bajo su auspicio el Diccionario de Autoridades, que sería reeditado recibiendo algunas modificaciones, pues en palabras de G. Clavería "desde su origen y durante parte del siglo XIX, aplicó un criterio restrictivo y normativo en la aceptación de neologismos científicos y técnicos, cuyo puesto debía ser, según su opinión, el diccionario especializado". La tendencia académica a ser demasiado resistente a la hora de incluir términos procedentes de las ciencias pujantes en el momento provocó reacciones diversas en el mundo intelectual, convirtiéndose en un debate plural la inclusión de voces de especialidad en los diccionarios generales ${ }^{7}$, criterio éste que parece ser más abierto a partir de la edición de 1884 , cuya aparición se convirtió en un acontecimiento ${ }^{8}$, puesto que hasta esta edición únicamente se recogían aquellos vocablos que se consideraran más comunes', abriéndose este conservadurismo por la aceptación que adquirieron, tal como se puede advertir en el léxico de la electricidad ${ }^{10}$.

5 Vid. Garriga Escribano (1996a, 1997 y 2002).

6 Vid. Clavería (2001: 207).

7 Vid. Azorín y Santamaría (1998: 362).

8 Vid. Garriga Escribano (2001b: 264).

9 Vid. Alvar Ezquerra (1983).

10 Vid. Moreno Villanueva (1995-1996). 
La polémica desatada tuvo sus consecuencias inmediatas en la lexicografía, pues si la labor lexicográfica era un campo exclusivo de la Academia en el siglo XVIII, tras la repercusión de las ciencias en el léxico del español se empezaron a editar numerosos diccionarios de autor que mostraban su desacuerdo con la tendencia restrictiva de la Academia, una semilla que aportó el diccionario de Terreros y Pando, "el primero que considera los tecnicismos como parte integrante y, a la vez, esencial de la lengua culta común" ${ }^{11}$. De él se alimenta la nueva corriente lexicográfica de este siglo que intenta reflejar el uso vivo de la lengua ${ }^{12}$ que será denominada "generación lexicográfica de 1850 " y en ella se incluyen autores como Salvá, Domínguez, Castro,... abarcando incluso campos hasta ahora poco considerados, como los diccionarios etimológicos ${ }^{13}$. Este trabajo al margen de la Academia se extiende por toda la centuria, elaborándose diccionarios prácticamente desconocidos, como los de Donadíu y Echegaray ${ }^{14}$, y estos diccionarios que incorporan en sus páginas un amplio corpus de tecnismos serán una fuente, un tanto oculta, para los ediciones de los diccionarios académicos de 1884 y 1899, advirtiéndose en ellos la reestructuración de lemas, cambios en las definiciones para aproximarlas a la ciencia, por eso los mariscos y las conchas pasan a ser moluscos y acéfalos, se crean nuevas acepciones y se observan cambios también en las marcas diatécnicas ${ }^{15}$.

Una vez presentado cuál era el panorama de las ciencias técnicas y su influencia y repercusión en el léxico especializado, comprobaremos su comportamiento en el ámbito de la Minería a través de los ejemplos extraídos de las publicaciones periódicas del momento. Para ello hemos recurrido, debido a la importancia que cobra la minería en Murcia durante el siglo XIX, a aquellos vocablos recogidos y editados

11 Vid. Azorín y Santamaría (1998: 363).

12 Vid. Anglada y Bargalló (1992) y Seco (1987).

13 Vid. Puche Lorenzo (2002) e Igualada Belchí (2002).

14 Vid. Garriga Escribano (1996b) y Puche Lorenzo (2000).

15 Clavería (2001: 207 y ss.). 
en los periódicos El Minero, Boletín de Minas y El minero de Almagrera $^{16}$. En estas publicaciones se narra el trabajo en las minas, se describe cómo se obtienen los diversos metales y minerales, se cuentan los novedosos métodos de explotación, los últimos instrumentos fabricados para su trabajo, se describen los diversos tipos de minerales,... y en su escritura se valen de una serie de términos unos técnicos y especializados, mientras que otros no lo son aunque pudieron haberlo sido en algún momento. Eran los medios adecuados para la difusión de una ciencia, de unos conocimientos en un periodo en el que los medios de comunicación estaban casi restringidos a la prensa escrita, entre un sector de la población que no creemos que fuera tan amplio ni estuviera tan preparado para conocer o comprender lo que en ellos se decía. Por este motivo, las siguientes declaraciones aparecidas en El Minero, 25 de mayo de 1841, pueden ser suficientemente significativas: "Y la verdad $¿$ a que hablar de ensayos de minerales a un público que en lo general ignora el nombre de los gases, de los ácidos, y hasta el peso específico de los metales? ¿Que no tiene ni aun las ideas de física, que ni sabe geognósica, ni hidráulica, ni hidrostática, ni matemáticas, ni en fin, ninguna de aquellas ciencias sin las quales es imposible dar un paso acertado, un golpe con tino, en la que se llama verdaderamente metalurgía?".

Ahora bien, proponemos para analizar los términos encontrados en los periódicos a los que hemos hecho referencia una doble división, pues por un lado atenderemos a la forma externa de los vocablos observando cuáles de ellos son palabras derivadas, cuáles préstamos léxicos y cuál es su adaptación a las normas gráficas de la lengua española, así como los diversos mecanismos que ayudarían a dotar de mayor comprensión a unos términos y fórmulas que no serían generales en la lengua común. Por otro lado, tras ver qué tipo de palabras han atraído nuestra atención, comprobaremos cuál fue la actitud de la lexicografía académica hacia ellos, es decir, cuándo fueron recogidos como parte del corpus léxico de un diccionario y qué características,

16 Se han consultado para este trabajo los ejemplares que se conservan en el Archivo Municipal de Murcia. 
con respecto a la marcación que recibieron, entre otras cuestiones, merecen destacarse.

Sin olvidar en ningún momento que el desarrollo de una actividad científica no se realiza de manera aislada y necesita de otras disciplinas auxiliares, también del ámbito de la ciencia, para su evolución. En el caso de la Minería, la relación más estrecha se mantiene con la Química, por motivos evidentes, pues muchos de sus adelantos y descubrimientos las han vinculado, aunque históricamente la antigüedad de la Minería y la inexistencia o desconocimiento de la Química se reflejó en que muchas de las voces que ahora mismo aproximamos al área de ésta, fueran propias de la primera, la Minería, tal como quedó registrado en las ediciones del diccionario académico, cuestión ésta en la que incidiremos conforme vayamos avanzando en este trabajo.

Los términos que hemos recogido reúnen una serie de peculiaridades externas que afectan al terreno gráfico, morfológico o, incluso, morfosintáctico. Dentro de las palabras simples, formadas por un solo lexema y sujetas a las marcas gramaticales de la flexión, si la palabra lo requiere, se encuentran los nombres de minerales y metales como hierro, plata, bronce, cobre, plomo, estaño, rubies, esmeraldas, zafiros, azogue, alumbre, antimonio, azufre, turba,... elementos que no eran novedosos en el momento y no se podían considerar neologismos. Sin embargo, junto a ellos aparecen otros no tan frecuentes en la época que se incorporan al caudal léxico del español. Los hay que se han mantenido invariables hasta ahora, en lo que respecta a su forma gráfica, como antracita, lignito, manganeso, cemento, hulla, bórax, asfalto, frente a cinc, préstamo del alemán, o coque, préstamo del inglés, que adaptaron su grafía a la del español sustituyendo $z$ por $c$ y $k$ por $q u$, respectivamente. Merece destacarse al respecto que mientras que $c$ inc fue aceptado y mantuvo la grafía $z$ del alemán cuando se recoge en el diccionario académico, hasta que en la edición de 1884 se adapta la grafía, coque, sin embargo, nunca tuvo entrada en el diccionario con la grafía inglesa $k$.

A continuación de los préstamos situamos aquellas palabras que se han obtenido aplicando alguno de los mecanismos de derivación, prin- 
cipalmente por sufijación. Estos mecanismos presentan gran riqueza en el léxico de la química ${ }^{17}$ y entre los sufijos que obtienen mayor recurrencia si sitúan -oso, -izo, -ifero e -ico ${ }^{18}$, siendo este último el único sufijo que en español posee acentuación átona debido a su origen culto, esta procedencia lo dotó de especial actividad para formar palabras relacionadas con las ciencias, ya fueran clásicas o modernas. Ejemplo de todo ello son las voces calizo, cobrizas, piritoso, argentifero, antimonifera, ferruginoso, metálica, metalúrgico, cúbica, octaédrica, dodaédrica, hidráulica, hidrostática, espático o feldespáticas .

Otro de los mecanismos que tiene presencia en los términos recogidos es la composición, la unión de dos lexemas que, sin llegar a obtener un alto grado de fusión gráfica entre ellos, sí están vinculados por un guión, que denominaremos composición por contraposición. Así se advierte en cubo-octaédrica, o las formaciones oxi-súlfuros y oxi-carbonatos en las que oxi-, más que un prefijo, podría ser considerado un prefijoide o un lexema, constituyendo en este último caso ejemplos de composición. Del mismo modo podremos hablar de composición por disyunción cuando la unión de los lexemas está subyugada a la presencia de un elemento de conexión, como la preposición de, en óxido de manganeso y sulfuro de arsénico.

Los sintagmas nominales son igualmente un recurso muy valioso a la hora de describir los nuevos elementos químicos y minerales que van apareciendo en este periodo, pues el sustantivo necesitará, en determinados casos, de un adjetivo denominal que aporte una mayor claridad a las descripciones: cobre argentifero, cobre piritoso, piritas cobrizas, carbonato calizo nos demuestran lo que hemos expuesto.

No queda ninguna duda de que las voces que vamos exponiendo son propias de una lengua técnica en plena efervescencia y actualidad durante el siglo XIX, por ello no es de extrañar que los textos que sirvieran para su difusión y divulgación utilizaran una serie de recursos comunes a otras lenguas técnicas, como es la lengua jurídica, como la

17 Vid. Gutiérrez Cuadrado (2001), Garriga Escribano (2001a) y Sala Caja (2001).

18 Vid. Pharies (2002). 
coordinación de sinónimos ${ }^{19}$ a través de lo que se busca aportar claridad y fácil comprensión a los elementos expuestos, sirviendo en determinados casos de la unión de un término técnico y otro más extendido en la lengua común como galena o alcohol de alfareros, sucino o ámbar amarillo, hulla o carbón de piedra, granular o acerada, irisada o pavonada, alcohol o sulfuro de plomo, cobre piritoso o pirita de cobre y cinabrio o sulfuro de mercurio. Este aspecto se ve aumentado y esclarecido cuando junto al término técnico se aporta otro vulgar, dejando clara constancia de ello como se indica en hierro micaceo o escamoso vulgarmente conocido con el nombre de voladillo.

No está de más comprobar cómo los usos metafóricos se extienden en el seno de una lengua técnica cuyos descubrimientos debían ir más deprisa que la creación lingüística y, por tanto, la comparación metafórica se convierte en un recurso nada despreciable. De hecho, para describir las diversas formas que adquiere la galena según la configuración de sus cristales se utilizan las diversas construcciones: galena palmeada, galena pavonada o galena de ojo de perdiz.

En el último apartado en el que nos centraremos es la percepción que recibe el Diccionario académico de los vocablos que aporta una labor científica en pleno apogeo durante el siglo XIX. Para ello es necesario incidir en algunos aspectos como saber cuándo se integran estas voces a los repertorios lexicográficos, qué tipo de marcación diatécnica llevan adjunta y si realiza alguna aportación la lexicografía no académica. No podemos olvidar en ningún momento que los periódicos consultados datan de 1841, El Minero y Boletín de Minas, y 1874, El minero de Almagrera.

Si recordamos todo lo que dijimos al principio, con la edición de 1884 del DRAE parece abrirse el carácter restrictivo que tenía la Academia en cuanto a la incorporación de voces técnicas, debido a la extensión que habían ido adquiriendo en la lengua común. Pero la Minería era una de esas técnicas en constante avance desde principios de siglo; por ello en ediciones anteriores, principalmente la de 1869, ha-

19 Vid. Díez de Revenga Torres (2001: 108), Isasi (2000) y Lagüéns (1992). 
bía entrado ya un amplio número de este tipo de términos. La evolución, por tanto, en cuanto a la entrada de voces de la Minería podría decirse que fue constante desde el Diccionario de Autoridades, donde palabras como plomo, cobre, ámbar, carbón, cinabrio, mercurio, alcohol, mina, antimonio o turba ya estaban recogidas.

Si realizamos un esquema con las diferentes ediciones del DRAE durante el siglo XIX, nos encontramos con la consiguiente distribución de los términos en relación con el momento en que fueron incorporados a éste; para ello indicamos el año de la edición y las voces que se introducen:

\begin{tabular}{|c|c|c|c|c|}
\hline 1803 & 1817 & 1822 & 1832 & 1837 \\
\hline $\begin{array}{l}\text { Metalúrgico } \\
\text { Asfalto } \\
\text { Laminar } \\
\text { Ferruginoso } \\
\text { Agiotista } \\
\text { Mineralogía }\end{array}$ & $\begin{array}{l}\text { Zinc } \\
\text { Cuarzo } \\
\text { Cobalto } \\
\text { Sucino } \\
\text { Mena }\end{array}$ & Pirita & $\begin{array}{l}\text { Espato } \\
\text { Óxido }\end{array}$ & $\begin{array}{l}\text { Galena } \\
\text { Geognosia } \\
\text { Cuarzoso }\end{array}$ \\
\hline 1843 & 1852 & 1869 & 1884 & 1899 \\
\hline $\begin{array}{l}\text { Argentífero } \\
\text { Criadero }\end{array}$ & $\begin{array}{l}\text { Sílice } \\
\text { Carbonato } \\
\text { Silíceo }\end{array}$ & $\begin{array}{l}\text { Lignito } \\
\text { Fosforita } \\
\text { Sosa } \\
\text { Bórax } \\
\text { Antracita } \\
\text { Manganeso } \\
\text { Blenda } \\
\text { Sulfuro } \\
\text { Irisar } \\
\text { Barita } \\
\text { Hulla }\end{array}$ & $\begin{array}{l}\text { Cemento } \\
\text { Concrecionada } \\
\text { Caliza } \\
\text { Magnesiana } \\
\text { Oligisto } \\
\text { Granular } \\
\text { Piritoso } \\
\text { Emboquillar } \\
\text { Refractario }\end{array}$ & $\begin{array}{l}\text { Coque } \\
\text { Espático } \\
\text { Feldespático } \\
\text { Micaceo }\end{array}$ \\
\hline
\end{tabular}

dejando, por el momento, hidráulico, hidrostática y litargirio que se introdujeron en la edición de 1780 y sulfatada que no será introducida hasta 1936.

Es, sobre todo, el periodo comprendido entre las ediciones de 1869 y 1884 el que resulta más productivo para la incorporación de los tér- 
minos procedentes de la Minería, aunque se podrá ir observando cómo la marcación diatécnica, minería o mineralogía (hasta la edición de 1869) y química, varía en las diferentes impresiones del diccionario en el trascurso del siglo. Por ello, en cuanto a la marcación diatécnica se refiere, nos encontramos con las siguientes maneras de delimitación técnica de los vocablos presentes en los periódicos consultados:

1. Términos que no tienen ningún tipo de marca: lumbrera, carbón, hulla, piritoso, pirita, cinabrio, micaceo, barita, vaciadero, argentifero, espático o caliza

2. Términos que en un principio estaban acotados, mediante una marca, a una disciplina científica que acaba desapareciendo en ediciones posteriores: blenda y antracita aparecen en 1869 bajo la marca de Química, que desaparece en 1884; cobalto en 1817, espato en 1832, galena en 1837 e irisar en 1869 poseían la marca de Mineralogía ${ }^{20}$ que en 1884 se suprime, como sucede con emboquillar que en 1914 no incluye la marca de Minería.

3. Términos que no aparecen marcados en un primer momento y con posterioridad la marca los incluye en un campo científico determinado: cobre y plomo incorporados desde Autoridades, adquieren la marca de Química en una de sus acepciones en la edición de 1970, ganga o pozo, también desde Autoridades, toman la marca de Mineralogía en 1869 y 1852, respectivamente; mena desde 1817 y sulfuro desde 1869, quedan restringidos al ámbito de la Minería en 1869 y Química en 1884.

4. Términos en los que la marca diatécnica va cambiando según las diferentes ediciones: mineralizado en 1822 (s. v. mineralizar), se muestra con la marca de la Química que en 1884 cambia a Minería o sílice que se introduce en 1852 con la marca de Mineralogía, en 1869 se informa de su pertenencia a la Mineralogía y a la Química, para llegar a la edición de1884 con la marcación exclusiva de la Química.

20 Hasta la edición de 1869 Min. era Mineralogía, en la de 1884 Min. se convierte en Minería y Miner. será Mineralogía. 
5. Términos que conservan la marcación que nos indica su pertenencia al terreno de la minería: criadero.

6. Términos con marcación exclusiva de la Química: refractario en 1884 con marcación de Física y Química, óxido, carbonato, sulfato, sosa o granular.

7. Términos cuya incorporación a un repertorio lexicográfico es anterior en los diccionarios no académicos: barita que aparece en los diccionarios de Núñez (1825) y Domínguez (1853) con la marca de Minería, cuando no se introduce en la DRAE hasta 1869 , irisada, introducida por la Academia en 1984, pero que ya tenía entrada en el diccionario de Domínguez (1853) o sulfatada en el DRAE en 1936, pero recogida por Domínguez (1853) y Gaspar (1855) con la marca de Química.

8. Divergencias entre las marcas introducidas por la Academia y los lexicógrafos no académicos: magnesiana (DRAE, 1884) como Química, pero Domínguez (1853) como voz de la Minería; laminar (DRAE, 1803) de la Aritmética, y Domínguez de la Minería; concrecionada (DRAE, 1884, s. v. concrecionar) no posee ningún tipo de marca, frente a Domínguez que también la incluye dentro de la Minería.

9. Términos que no están incluidos en los diccionarios académicos: minomanía, rendido, artero, barreras arterianas o voladillo, junto a otros que, si bien no están incluidos, la lexicografía no académica sí los registró como mineralizado o antimonífera.

Por último, estos cambios no afectaron solamente a la marcación diatécnica, pues en las definiciones también se observa cómo los diversos adelantos promovidos por las ciencias provocaban que éstas fueran variando, acordes con la terminología extendida entre ellas. Un claro ejemplo nos viene con mena que en 1817 era "La veta del mineral y el mismo mineral", en 1869 "Los minerales o metales mezclados todavía con la ganga o con la piedra y tierra de la mina" y en 1884 "Mineral metalífero, principalmente el de hierro, tal como se extrae del criadero y antes de limpiarse", copelar en Autoridades "Lo mismo que cendrar" y en 1869 "Fundir minerales o metales en copela para ensayos, o en hornos de copela para operaciones metalúrgicas", cinabrio, desde Autorida- 
des tenía la acepción de "Vermellón" y en 1884 "Mineral compuesto de zufre y mercurio, color rojo oscuro. Del cinabrio se extrae, generalmente por sublimación, el mercurio o azogue metálico".

Después de todo lo expuesto hemos podido comprobar como durante todo el siglo XIX se está produciendo una constante introducción de términos relacionados con la Minería, sin olvidar que, sin embargo, se realiza esta incorporación con retraso al uso que se hace de ellos en la lengua, si tenemos en cuenta la fecha de los periódicos de los que hemos extraído los ejemplos y la fecha en que fueron introducidos en el $D R A E$. Los vocablos que hemos utilizado para este trabajo no siempre incluyen una marca diatécnica que los aproxime a un área científica: de hecho, al ser este un siglo en constante evolución, la relación entre Química y Minería se hace más estrecha, algo que se percibe en la propia marcación de los términos; del mismo modo, la desaparición de las marcas en ediciones sucesivas no deja sino que traslucir la generalización de las palabras en la lengua general.

En cuanto a la incorporación de estos tecnicismos, hemos observado cómo la lexicografía no académica se adelantó en muchas ocasiones a la Academia a la hora de introducir nuevos cambios, resultando un fiel espejo del uso de la lengua en el siglo XIX. Para finalizar, y en un intento de destacar la importancia del estudio del léxico del español, quiero servirme de las palabras del Prof. Messner porque tal investigación no es fácil sobre todo "en una época en que el cambio de los paradigmas culturales tiene consecuencias fatales sobre la investigación porque han desaparecido los conocimientos tradicionales que tuvimos de la religión, de la antigüedad y de las lenguas clásicas"

21 Vid. Messner (2002), texto facilitado por el autor. 


\section{BIBLIOGRAFÍA}

Almela, Ramón (1999): Procedimientos de formación de palabras en español, Barcelona, Ariel.

Alvar EzQuerra, Manuel (1983): “Los prólogos del ‘Diccionario’ académico. Nomenclatura específica y microestructura”, Revista de Filología Española, LXIII, pp. 205-222.

(1996): La formación de palabras en español, Madrid, Arco/Libros. Anglada, Emìlia y María BARgalló (1992): "Principios de lexicografía moderna en diccionarios del siglo XIX", en M. Ariza et al. (eds.), Actas del II Congreso Internacional de Historia de la Lengua Española, Madrid, Pabellón de España-Arco/Libros, pp. 955962

Azorín, Dolores y M. Isabel SANTAMARÍA (1998): “Los lenguajes de especialidad en los diccionarios del español de la primera mitad del siglo XIX", en J. Brumme (ed.), Actes del Col-loqui La historia dels llenguatges iberoromànics d'especialitat (segles XVII-XIX). Solucions per al present, Barcelona, IULA-Universitat Pompeu Fabra, Barcelona, pp. 359-379.

BAJo PÉRez, Elena (1997): La derivación nominal en español, Madrid, Arco/Libros.

ClaveríA, Gloria (2001): "El léxico especializado en la lexicografía de finales del siglo XIX: la decimotercera edición (1899) del Diccionario de la lengua castellana de la Academia", en J. Brumme (ed.), La historia de los lenguajes iberorrománicos de especialidad. La divulgación de la ciencia, Barcelona, IULA-Universitat Pompeu Fabra, pp. 207-222.

Díez de Revenga Torres, Pilar (2001): "Innovación y tradición en las lenguas de especialidad: el ejemplo de la lengua jurídica", en M. Bargalló et al. (eds.), Las lenguas de especialidad y su didáctica. Actas del Simposio Hispano-Austriaco, Tarragona, Universitat Rovira i Virgili, pp. 103-111.

DRAE-2001: Real Academia Española, Diccionario de la lengua española. Madrid, Espasa-Calpe ${ }^{22}$.

FORT, Ma Rosa (2001): "Terminología específica y su difusión en la lengua común", en M. Bargalló et al. (eds.), Las lenguas de especialidad y su didáctica. Actas del Simposio Hispano-Austriaco, Tarragona, Universitat Rovira i Virgili, pp. 113-124.

Frago Gracia, Juan Antonio (1989): “El marco filológico del Vidal Ma- 
yor", Vidal Mayor. Estudios, Huesca, Instituto de Estudios Altoaragoneses, pp. 85-112.

GARRIGA ESCRIBANO, Cecilio (1996a): "Apuntes sobre la incorporación del léxico de la química al español: la influencia de Lavoisier", en J. García-Bascuñana, B. Lépinette y C. Roig (eds.), Documents pour l'histoire du français langue étrangère ou seconde. Actes du colloque de la SIHFLES tenu à Tarragone (Université Rovira i Virgili) du 28 au 30 septembre 1995, SIHFLES, Décembre 1996, 18, pp. 419-435.

(1996b): "Delfín Donadíu, lexicógrafo desconocido del s. XIX", Crisol, 1, pp. 43-58.

(1997): "La recepción de la Nueva nomenclatura química en español", Grenzgänge, 4/8, pp. 33-48.

(2001a): "Notas sobre el vocabulario de la química orgánica en español: Liebig y la divulgación de los derivados en -ina", en M. Bargalló et al. (eds.), Las lenguas de especialidad y su didáctica. Actas del Simposio Hispano-Austriaco, Tarragona, Universitat Rovira i Virgili, pp. 169-180.

(2001b): "Sobre el Diccionario Académico: 1a 12a ed. (1884)", en A. M. ${ }^{a}$ Medina Guerra (coord.), Estudios de lexicografía diacrónica del español, Málaga, Universidad de Málaga, pp. 263-315.

(2002): "Notas sobre la incorporación de los términos de elementos químicos al español en el s. XIX: el Léxico Histórico y Sinonímico de F. Hoefer", en B. Pöll y F. Rainer (eds.), Vocabula et vocabularia, Frankfurt am Main, Peter Lang, pp. 131-144.

GÓMEZ DE ENTERRÍA, Josefa (2001): "Neologismos que llegan hasta el español de la segunda mitad del siglo XVIII a través de los textos de la divulgación científica”, en J. Brumme (ed.), La historia de los lenguajes iberorrománicos de especialidad. La divulgación de la ciencia, Barcelona, IULA-Universitat Pompeu Fabra, pp. 79-88.

GutiérRez CuAdrado, Juan (2001): "Lengua y ciencia en el siglo XIX español: el ejemplo de la química", en M. Bargalló et al. (eds.), Las lenguas de especialidad y su didáctica. Actas del Simposio Hispano-Austriaco, Tarragona, Universitat Rovira i Virgili, pp. 181-196.

IgUALADA Belchí, Dolores Anunciación (2002): "Sobre la técnica lexicográfica en el siglo XIX. El Diccionario General Etimológico de Roque Barcia", en M. Campos Souto y J. I. Pérez Pascual (eds.), De historia de la Lexicografia, Noia, Toxosoutos, pp. 137-147.

IsASI, Carmen (2000): "Los documentos notariales entre el formulismo y 
la innovación", en Estudios de Filología y Retórica en Homenaje a Luisa López Grigera, Bilbao, Universidad de Deusto, pp. 281-294. LAGÜENS, Vicente (1992): "Semántica jurídica: binomios léxicos en la prosa notarial", en M. Ariza et al. (eds.), Actas del II Congreso Internacional de Historia de la Lengua Española, Madrid, Pabellón de España-Arco/Libros, pp. 1121-1128.

LANG, Mervyn F. (1992): La formación de palabras en español, Madrid, Cátedra.

Messner, Dieter (2002): “Comentarios muy personales sobre cien años de estudios históricos del léxico español”, Conferencia inédita pronunciada en el curso de verano "El legado de Menéndez Pidal hoy (Cien años de Filología Española)", San Lorenzo de El Escorial, 59 de agosto de 2002.

Moreno VillanUeVA, José Antonio (1995-1996): "La recepción del léxico de la electricidad en el DRAE: de Autoridades a 1884", Revista de Lexicografía, II, pp. 61-72.

PENA, Jesús (1999): "Partes de la morfología. Las unidades del análisis morfológico", en I. Bosque y V. Demonte (dirs.), Gramática descriptiva de la lengua española, III, Madrid, Espasa, pp. 4305-4366, (2000): "Formación de palabras", en M. Alvar (dir.), Introducción a la Lingüística Española, Barcelona, Ariel, pp. 235-253.

PhARIES, David (2002): Diccionario Etimológico de los sufijos españoles, Madrid, Gredos.

Puche Lorenzo, Miguel Ángel (2000): "El Diccionario Etimológico de la Lengua Española de Echegaray. Un ejemplo de lexicografía decimonónica", Revista de Investigación Lingüística, 2/III, pp. 379-392.

(2002): "Los diccionarios etimológicos en el siglo XIX: de Roque Barcia a Eduardo de Echegaray", en M. Campos Souto y J. I. Pérez Pascual (eds.), De historia de la Lexicografía, Noya, Toxosoutos, pp. 181-191.

SAla CAJA, Lidia: "El desarrollo de la nomenclatura de los ácidos en el siglo XIX: -orto”, en M. Bargalló et al. (eds.), Las lenguas de especialidad y su didáctica. Actas del Simposio Hispano-Austriaco, Tarragona, Universitat Rovira i Virgili, pp. 289- 296.

SECO, Manuel (1987): "El nacimiento de la lexicografía moderna no académica", en Estudios de lexicografía española, Madrid, Paraninfo, pp. 129-151. 